\title{
Вклад геофизических исследований в изучение строения Хибин
}

\section{Жирова А.М.}

Геологический институт КНЦ РАН, Anamuты, anzhelaz@geoksc.apatity.ru

Аннотация. В статье даётся обзор геофизической изученности Хибинского массива, интерес к которому связан с крупнейшими фосфатными месторождения в регионе. За годы исследования применялись такие методы геофизики как сейсморазведка, гравиразведка, аэромагнитная съемка, магниторазведка в комплексе с высокоточной гравиметрии. Впервые для изучения рудных объектов применялась сейсморазведка методом отражённых волн. Приповерхностная часть массива в районе рудных тел была изучена достаточно хорошо на основе бурения многочисленных скважин с последующим геофизическим их исследованием. На основе полученных материалов построены многочисленные комплексные геолого-геофизические разрезы, обобщенные схемы строения и комплексная 3D геофизическая модель Хибин.

Ключевые слова: Хибинский массив, изученность геофизическими методами, сейсмогеологический разрез; 3D-моделирование, комплексная модель строения Хибинского плутона.

\section{Contribution of geophysical research to the study of the Khibiny structure}

Zhirova A.M.

Geological institute KSC RAS, Apatity,anzhelaz@geoksc.apatity.ru

\begin{abstract}
The article reviews the geophysical research of the Khibiny massif, the interest in which is associated with the largest phosphate deposits in the region. During the years of research, such methods of geophysics as the seismic and gravity prospecting, aeromagnetic survey, magnetic prospecting with high-precision gravimetry were used. For the first time, the method of reflected waves of seismic exploration was used to study ore objects. The near-surface part of the massif in the area of ore bodies was studied quite well, based on the drilling of numerous bores, followed by their geophysical study. On the basis of the materials obtained, numerous complex geological and geophysical sections, generalized structural schemes and a complex 3D geophysical model of the Khibiny were constructed.
\end{abstract}

Key words: Khibiny massif, geophysical research, seismogeological section, 3D-modeling, complex model of structure of the Khibiny pluton.

\section{Введение}

Хибинский щелочной массив располагается на Кольском полуострове - классической области развития щелочного магматизма, характеризующегося крупнейшими массивами нефелиновых сиенитов и многочисленными интрузиями щелочных-ультраосновных пород с карбонатитами. Строение и геология Хибинского массива вызвали интерес геофизиков ещё в 30-е годы прошлого века в связи с крупными месторождениями апатитовых руд, а также редкометальными месторождениями, с которыми связан массив. Первые геофизические работы, начатые в эти годы, получили своё планомерное развитие в дальнейшем усилиями различных исследователей, таких как Г.Н. Шаблинский, Н.А. Каверзнева, В.И. Богданов, И.И. Сорокина, А.В. Роллер, А.Л. Ронин, В.А. Тюремнов, О.Л. Сняткова, Н.И. Пронягин, В.И. Павловский, Г.А. Иванов и многих других. Построены многочисленные геолого-геофизические разрезы в пределах массива, компиляционные схемы строения, а также объёмные модели глубинного строения Хибин на основе модельных исследований.

\section{Геофизические исследования Хибин}

На ранних этапах исследования массива проводилось картирование коренных пород, а также изучение фоидолитов, и выделение в них зон, обогащённых такими полезными ископаемыми, как апатит и сфен. Глубинная структура Хибинского массива и строение ийолит-уртитовой дуги являлись первоочередными задачами, стоявшие перед геофизикой. Основными методами исследования были методы структурной геофизики - сейсморазведки, гравиразведки, аэромагнитной съемки (Шаблинский, Каверзнева, 1965). При этом вначале производились поиски рудных объектов, выходя- 
щих на поверхность коренных пород, но перекрытых чехлом четвертичных отложений. Основными методами картирования и оконтуривания этих объектов были магниторазведка с высокоточной гравиметрии. Следующий этап исследования Хибин был связан с поиском и разведкой глубокозалегающих рудных тел и структур, с которыми может быть связано это оруденение. Поскольку апатитовые месторождения массива приурочены к интрузии фоидолитов, то исследование тектоники данной интрузии явилось одной из важнейших задач геофизических методов разведки этого периода (Шаблинский, 1967).

В целом можно отметить, что изучение структуры Хибинского массива продвигалось по двум основным направлениям: изучение контактов массива и структуры ийолит-уртитовой толщи. Важно отметить, что до проведения геофизических исследований в 1960-62 г.г. предполагалось, что фоидолитовая интрузия имеет коническую форму (Елисеев, Ожинский, Володин, 1939), в центре которой находится толща фойяитов, нефелиновых сиенитов и рисчорритов. После изучения массива методами аэромагниторазведки и гравиразведки по отдельным маршрутам, установлено, что висячий бок интрузии по направлению к центру интрузии быстро выполаживается и его углы падения уменьшаются до $0 \div 10^{\circ}$. В центре массива верхнюю границу фоидолитов можно встретить на глубине $3 \div 4$ км. Таким образом, в результате геофизических исследований, была уточнена форма интрузии и установлено, что она имеет не конусообразную форму, а форму лакколита.

В более поздние годы (Сняткова, Пронягин, 1983) с целью изучения структуры фоидолитового комплекса применялась сейсморазведка методом отражённых волн (МOB), в результате чего были построены детальные разрезы. Глубинная тектоника и структура массива Хибинского массива изучалась сейсморазведкой, гравиразведкой и аэромагниторазведкой (Шаблинский, 1963 a). При исследовании контакта Хибинского массива с породами свиты Имандра-Варзуга ведущим методом была гравиразведка, с помощью которой над контактом пород выявлена чёткая аномалия силы тяжести.

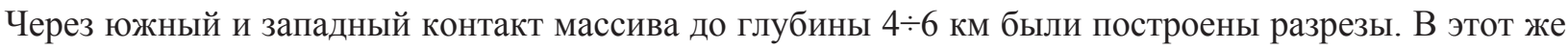
период была использована сейсморазведка МОВ для проверки результатов гравиразведки, а также исследования северного контакта массива, где развиты гнейсы, имеющие плотность, практически равную плотности пород Хибинского массива. В результате установлено, что наблюдаемые волны являются волнами, отражёнными от границ, находящихся в кристаллических породах, а на площади Хибинского и Ловозёрского массивов не удалось найти ни одного участка, где были бы зарегистрированы вступления отражённых волн, идущих из толщи щелочных изверженных пород. Глубинная граница плутона отмечалась как граница между областью существования многочисленных отражающих площадок и областью их полного отсутствия.

На основании данных геофизических работ Г.Н. Шаблинским (Шаблинский, 1963а) сделаны следующие выводы о глубинном строении Хибинского плутона. На севере его контакт с вмещающими гнейсами прослеживается на глубину до 6 $\div$ км, причём на всем интервале этих глубин отмечается крутое падение контакта под углом $81^{\circ}$ в сторону массива. Западный контакт плутона также

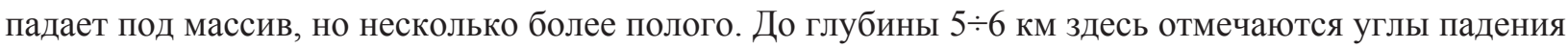
порядка $70^{\circ}$, затем наблюдается тенденция к выполаживанию контакта, который на глубине $6 \div 7$ км характеризуется углами падения $40 \div 50^{\circ}$. Южные и юго-западные районы Хибинского плутона по геофизическим данным имеют лополитообразную форму.

Позднее результаты исследований методом отражённых волн (Шаблинский, 1963б) были пересмотрены последующими исследователями (Роллер, Ронин, 1978) в свете развития методов рудной сейсморазведки. Выполнены профильные сейсмические работы методом отражённых волн, и во внутренних точках среды методом вертикального сейсмопрофилирования (Роллер, Ронин, 1978). Установлены устойчивые и протяжённые группы отражений, связанные с Хибинским и Ловозёрским массивами. Сделан вывод о том, что Хибинский массив имеет форму асимметричного лополита с мощностью до 10 км. При этом устанавливается закономерное выполаживание контактов отдельных интрузивных комплексов с глубиной.

Важно отметить, что приповерхностная часть массива в районе рудных тел ийолит-уртитовой дуги была изучена достаточно хорошо, поскольку в этой части Хибин проводилось бурение много- 
численных скважин. Бурение колонковых скважин глубинами до первых сотен метров проводилось с последующим геофизическим их исследованием (ГИС) различными методами. Так, выполнялись ГИС-исследования скважин методами нейтронного активационного каротажа, гамма-гамма метода измерения плотности, каротажа магнитной восприимчивости и гамма-метода (О результатах оценки..., 2005). Полученные материалы использовались для построения по скважинам комплексных геолого-геофизических разрезов.

\section{Обобщение и анализ результатов геофизических исследований Хибин}

Основываясь на геофизических исследованиях, проведённых в регионе в течение многих лет его освоения, А.В. Галаховым была построена обобщённая схема глубинного строения Хибинского массива (рис. 1). Основная масса отражающих площадок установлена в восточной и центральной части, а также в районе массивных хибинитов и их контактов с комплексом Имандра-Варзуга. На их основе проведены условные сейсмические границы. В целом по разрезу А.В. Галахова (рис. 1) (Галахов, 1975) можно отметить, что геологическое строение верхней части и контакты плутона изучены геолого-геофизическими методами достаточно хорошо, однако строение на глубине - условное и корневая часть массива практически не освещена.

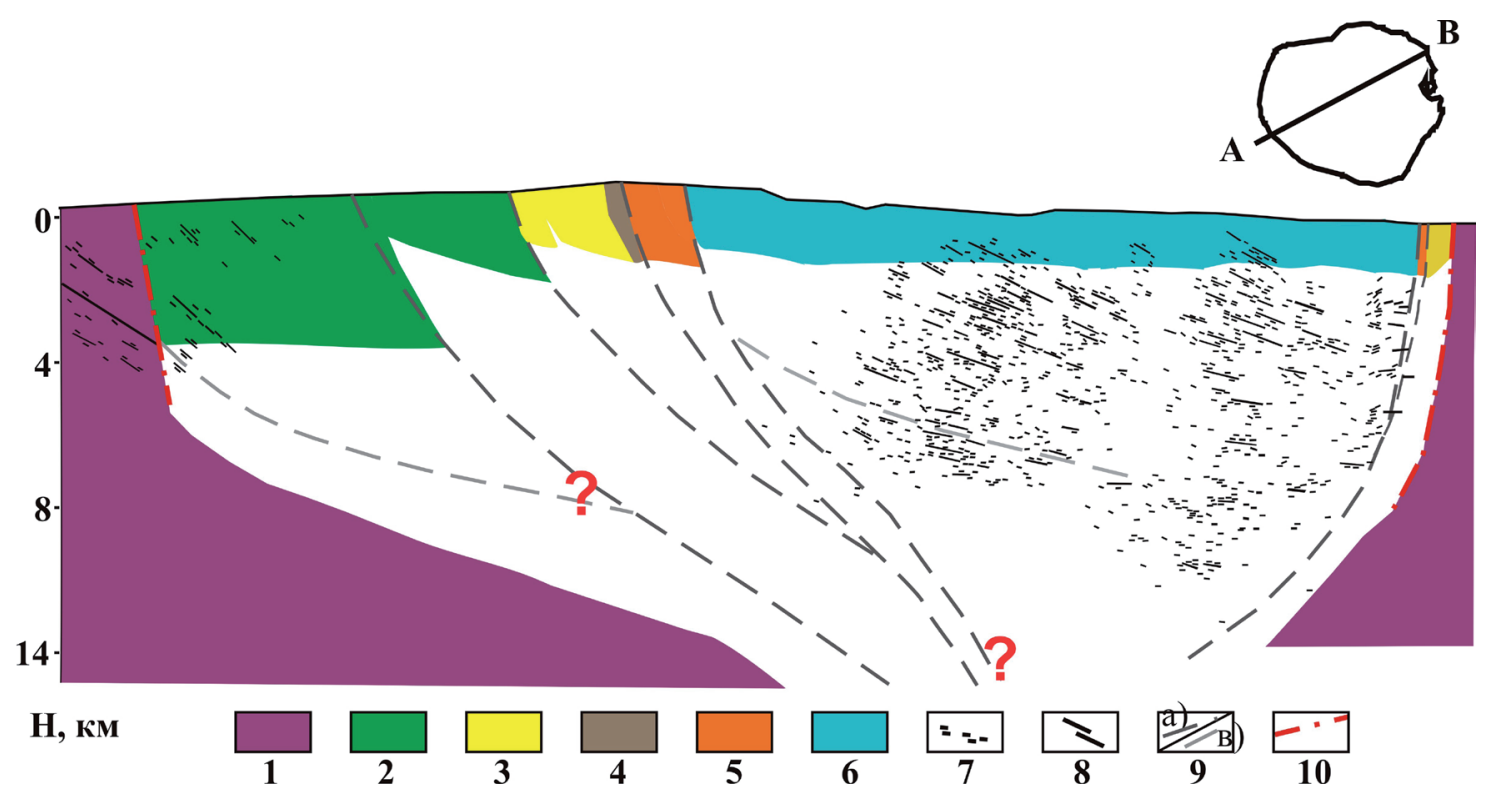

Рис. 1. Компиляционная схема глубинного строения Хибинского массива (Галахов, 1975).

1 - архейские и протерозойские породы, 2 - хибиниты, 3 - рисчорриты, 4 - малиньиты, 5 - лявочорриты, 6 - фойяиты, 7 - отражающие площадки, 8 - условные сейсмические границы, 9 - контакты между интрузиями массива: а) между субфазами одной интрузии; б) 10-контакты массива по геофизическим данным.

Fig. 1. Compilation scheme of the deep structure of the Khibiny massif (Galakhov, 1975).

1 - Archean and Proterozoic rocks; 2 - khibinites; 3 - rischorrites; 4 - malignites; 5 - lyavocharites; 6 - foyaites; 7 - reflecting areas; 8 - conditional seismic boundaries; 9 - contacts between the intrusions of the massif: a) between subphases of one intrusion; b) 10-contacts of the massif according to geophysical data.

Следующий этап изучения Хибинского массива был связан с моделированием его строения. Так, В.Н. Глазневым и другими исследователями (Арзамасцев, Беа, Беляцкий и др., 2002) выполнено петроплотностнное моделирование, в результате которого получено конически-кольцевое строение плутона до глубины 10 км (рис. 2).

Объёмная сейсмическая модель массива была построена в рамках работ по изучению 3D-строения Лапландского гранулитового пояса и соседних структур, которая частично включала и Хибинский массив (Буянов, Глазнев, Митрофанов и др.,1996). Сейсмическая модель вошла как одна из составных частей единой комплексной модели региона исследований. 


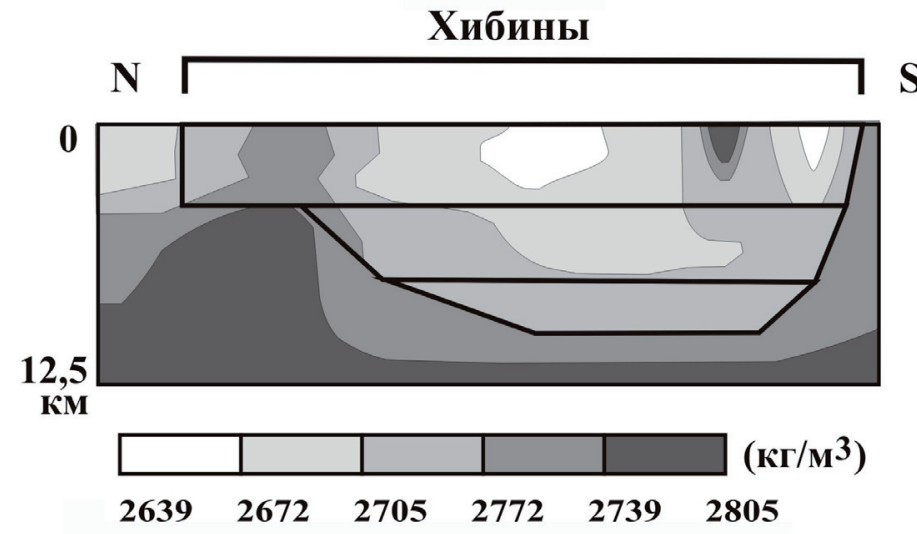

Рис. 2. Плотностной разрез Хибинского массива по результатам 3D-моделирования В.Н. Глазнева и др. (Арзамасцев, Беа, Беляцкий и др., 2002).

Fig. 2. Density profile of the Khibiny massif according to results of 3D-modeling of V.N. Glaznev et al. (Arzamastsev, Bea, Belyatsky et al., 2002).

дна. Установлено, что выполаживание юго-западного контакта массива с протерозойскими эффузивами происходит на уровне менее 4 км. Для донной части массива получена оценка глубины, равная $11 \div 12$ км. Спецификой глубинного строения массива является наличие аномальных объектов, установленных на глубинах $2 \div 5$ км. Можно предположить, что эти аномальные тела представляют фрагменты палеокальдеры Хибинского массива. Детальное выяснение геологической природы выявленных глубинных геофизических неоднородностей требует привлечения петрологических данных по щелочным породам региона.

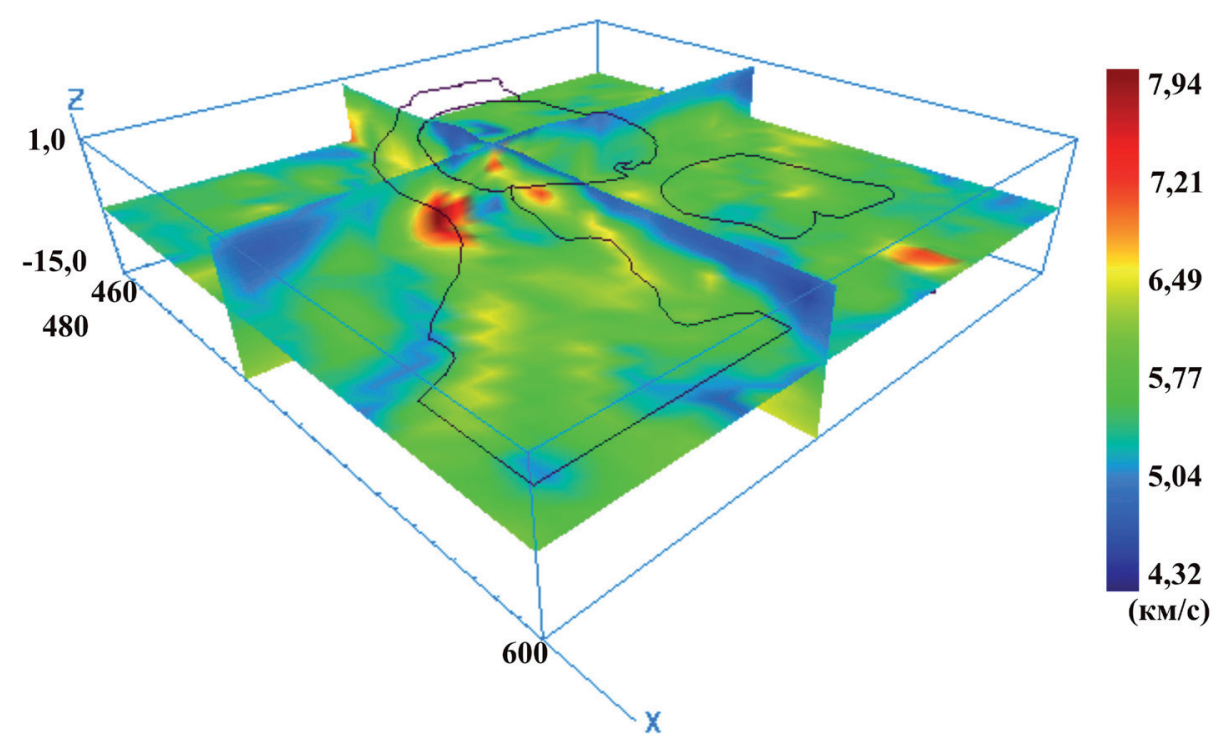

Рис. 3. 3D-комплексная модель строения земной коры в районе Хибинского и Ловозерского массивов, представленная в значениях скорости продольных волн (км/с) (Глазнев, Жирова, Раевский, 2007).

Fig. 3. 3D-complex model of the structure of the Earth's crust in the area of the Khibiny and Lovozero massifs, presented in the values of the velocity of longitudinal waves (km/s) (Glaznev, Zhirova, Raevsky, 2007).

Работа выполнена в рамках темы НИР № 0226-2019-0053. 


\section{Литература}

1. Арзамасцев А.А., Беа Ф., Беляцкий Б.В. и др. Палеозойские процессы плюм- литосферного взаимодействия в северо-восточной части Балтийского щита: длительность, объемы, условия магмогенерация: сб. статей / Геология и полезные ископаемые Кольского полуострова. Апатиты: КФАН СССР. 2002. С. 104-145.

2. Буянов А.Ф., Глазнев В.Н., Митрофанов Ф.П. и др. Трёхмерное строение Лапландского гранулитового пояса и соседних структур Балтийского щита по геофизическим данным // Региональная геология и металлогения. 1996. № 5. С. 48-63.

3. Галахов А.В. Петрология Хибинского щелочного массива. Л.: Наука. 1975. 256 с

4. Глазнев В.Н., Жирова А.М., Раевский А.Б. Сейсмоплотностная модель гигантских щелочных массивов Хибин и Ловозера (Кольский полуостров) // Материалы 34-й сессии Международного семинара им. Д.Г.Успенского «Вопросы теории и практики интерпретации гравитационных, магнитных и электрических полей». Москва: ИФЗ РАН. 2007. С. 78-81.

5. Елисеев Н.А., Ожинский И.С., Володин Е.Н. Геологическая карта Хибинских тундр // Труды Ленингр. геол. упр-я. 1939. Вып. 19. 68 с.

6. О результатах оценки промышленной значимости сателлитовых рудных тел на участках «Нагорный» и «Ийолитовый отрог» (Хибинский массив) за 2001-2005 гг.: отчёт (заключительн.) / Открытое акционерное общество «Апатит» ОАО «Мурманская геологоразведочная экспедиция»; исполн.: Ф.В. Минаков и др. Апатиты. 2005. 4 книги. 1 папка. № N51-2002-13/1.

7. Роллер А.В., Ронин А.Л., Пронягин Н.И. Применение метода отражений волн при изучении глубинного строения Хибинского массива: сб. статей / Методы разведочной геофизики. Рудная сейсморазведка. Л. 1978. C. 96-102.

8. Сняткова О.Л., Пронягин Н.И. Новые данные о структуре апатит-нефелиновых месторождений // Разведка и охрана недр. 1983. № 7. С. 10-14.

9. Шаблинский Г.Н. К вопросу о глубинном строении Хибинского и Ловозерского плутонов // Труды Ленингр. об-ва естествоиспытателей, 1963а. Т. 74. № 1. С. 41-43.

10. Шаблинский Г.Н. Метод отражённых волн при исследовании глубинного строения щелочных массивов Кольского п-ова // Записки ЛГИ. 1963 б. Т. 46. № 2. С. 28-32.

11. Шаблинский Г.Н., Каверзнева Н.А. О применении геофизических методов для поисков апатитовых руд // Разведка и охрана недр. 1965. № 9. С. 32-35.

12. Шаблинский Г.Н. Очередные задачи геофизических работ при поисках апатитовых руд на Кольском полуострове: сб. статей / Опыт применения радиоактивных и других физико-химических методов при поисках и разведке руд. Л: Недра. 1967. С. 107-112. 